\title{
Comparison of Prediction Methods for Axial Strength of Grouted Connections with Shear Keys
}

\author{
You Xianhui, Wu Zhaoqi * and Chen Zehao \\ College of Civil Engineering, Fuzhou University, Fuzhou, Fujian 350108, China; youxianhui@fjyongfu.com (Y.X.); \\ chenzehao@zldcgroup.com (C.Z.) \\ * Correspondence: zhaoqi_wu@fzu.edu.cn; Tel.: +86-186-5075-6886
}

Received: 31 January 2020; Accepted: 7 March 2020; Published: 12 March 2020

\begin{abstract}
Grouted connections are commonly used in marine engineering, especially on oil platforms, cross-sea bridges, and offshore wind power turbines. The prediction methods for axial carrying capacity of grouted connections with shear keys and their application ranges in current codes were analyzed in this paper. The calculated results by using different codes were compared based on a practical grouted connection between steel piles and the jacket foundation of a wind turbine. The research team conducted axial compression tests on seven specimens, collected a wide range of experimental results to establish a database, and finally compared the standard calculation results with the experimental results. The study indicates that the axial strength of grouted connections predicted by different methods is distinct. The calculation formula of the British Health and Safety Executive (HSE, 2002) has obvious limitations; specifically, with increased shear keys, strength is overestimated, resulting in insecure design outcome of structures. The results calculated by the Norwegian Det Norske Veritas (DNV, 2013) are generally consistent with the experimental results, in which the reduction effect of multiple shear keys was considered. The prediction method of the American Petroleum Institute (API, 2007), which undervalues the bearing performance of connections, is excessively conservative. The method of the combined Norwegian and German Det Norske Veritas-Germanischer Lloyd (DNV-GL, 2016) has wider applicability and is safe, reliable, and economical.
\end{abstract}

Keywords: grouted connection; shear key; axial carrying capacity; comparison between codes; experimental result; predicate method

\section{Introduction}

A grouted connection is a lap connection between two steel tubes of different diameters. The cement-based high-strength grouting material is poured into the annular space formed between two steel tubes. The grouted connection transfers internal forces through shear and friction between the pipe wall and the grouting body. In the marine environment, implementation of the project is affected not only by wind, surge, humidity, strong corrosion, and other environmental factors, but also by the construction technology. Especially when the connection between the pile foundation structure and the superstructure is required to be completed under water, it is very difficult to implement the connection. Based on the practice of different connection modes, grouted connections are widely used in offshore engineering because of their advantages of good integrity, convenient construction, and lower cost. More and more offshore platforms and structures are being connected in this way, such as oil production platforms, cross-sea bridges, offshore wind power structures, etc. With the development of offshore wind power, grouted connections have gradually been applied to foundation structures for offshore wind turbine power infrastructure. According to the statistics of offshore wind turbines built in Europe, $60 \%$ of foundations have adopted grouted connections [1]. Although grouted 
connection has been actively applied in marine engineering, its development is not acceptable when compared with land engineering counterparts, so the relevant research output is relatively limited, and there is an urgent need for more research work to be carried out.

With and without a shear key installed are the two major types of grouted connection. The shear key can significantly increase the axial strength of the grouted connection. In recent years, slip settlement of offshore wind turbine tower foundations without shear key grouted connections has been spotted in Europe. Subsequently, grouted connections with shear keys or conical joints became a concern and some codes stipulated that grouted connections transferring axial force should not use connections without shear keys. The current regulations concerning the design for grouted connections with shear keys mainly include a document on pile/sleeve connections by the British Health and Safety Executive (HSE, 2002) [2]; the Recommended Practice for Planning, Designing, and Constructing Fixed Offshore Platforms by the American Petroleum Institute (API, 2007) [3]; the standard on petroleum and natural gas industries: fixed steel offshore structures by the International Organization for Standardization (ISO, 2007) [4]; the standard on the design of steel structures by the Norwegian Oil and Gas Association (NORSOK, 2013) [5]; and standards on support structures for wind turbines and design of offshore wind turbine structures by Det Norske Veritas and Germanischer Lloyd (DNV GL, 2016; DNV, 2013) [6,7].

Research on grouted connections started in the early 1970s, and many scholars have conducted significant studies of related research during the last few decades. Through experiments, Billington et al. $[8,9]$ proposed a formula for calculating the shear strength of a grouting connection section and the corresponding parameter relationship, which was adopted by HSE. Karsan et al. [10] also obtained the calculation formula of carrying capacity through the test data, which was embedded in the API's standards. These early studies mainly focused on specific projects, resulting in single rather than systematic study output, so limitations on the calculation formulas were unavoidable. In order to get more accurate calculation methods, further studies have been conducted. In combination with practical engineering, Lotsberg et al. [11] revealed that the axial bearing performance of a grouted connection was much more affected by the diameter and surface manufacturing error of the connection segment than that described in the specification. Dallyn et al. [12] obtained the correlation of these parameters through a great deal of parameter analysis and provided suggestions for ensuring the design reliability of bearing performance. In addition, they [13] also analyzed the impact of abrasion of the steel and grouting contact surface on the strength of grouting materials through experiments. Wang [14] and Zhang et al. [15] studied the axial bearing performance of grouted connections with different parameters, and established a regression equation between the shear stress and the radial stiffness of the grouting pipe. Through continuous exploration by scholars all over the world, the strength calculation formula of the grouted connection has been constantly improved; still, it is worth conducting further in-depth research given the complexity of its bearing mechanism.

Based on the previous research, prediction methods for the axial strength of grouted connections were proposed in the European and American codes. It is difficult for engineers to choose suitable codes. As with most problems in marine engineering, the prediction methods for axial strength of grouted connections is a concern of engineers. Due to the different sources of prediction methods, different characteristics are revealed in the methods. There is currently no analysis and comparison of different prediction methods using a large amount of experimental data. In this paper, the prediction methods for axial strength of grouted connections proposed in different codes are compared and the applicability and safety of different methods are analyzed. Some advice for marine structural engineers is provided. A reasonable design method is suggested to design grouted connections in marine engineering. Above all, the application scope and prediction methods of different codes are compared and analyzed. Then, taking a practical grouted connection between steel piles and the jacket foundation of a $4 \mathrm{MW}$ wind turbine as a prototype, a comparison of the axial strength obtained from different codes is performed through parameter conversion. In addition, axial compression tests are conducted on seven specimens. Using the detailed test data, finite element model parameter fitting work is carried out, and reliable finite element model parameters are obtained. A wide range of 
experimental results are collected to set up a database, which is also supplemented with finite element analysis, and finally the standard calculation results are compared with the experimental results.

Through experiments, finite element numerical simulation, and data analysis, this paper reveals that the results of axial strength obtained by different calculation methods are different. The applicable conditions of different codes are analyzed, with an evaluation of the associated economy and safety. The conclusions can provide a reference for the subsequent design of strong grouted connections.

\section{Methodology for Predicting Axial Strength}

\subsection{Comparison of Application Range}

The design requirements for grouted connections in the codes mentioned above are basically similar, but there are some differences. According to various codes, the structure of axial loading grouted connections and the performance requirements of grouting materials are summarized, as shown in Table 1 . The physical meanings of the geometric parameters in the table are shown in Figure $1 ; f_{\mathrm{cu}}$ is the compressive strength of the grouted body.

Table 1. Geometric and material parameters in different codes. DNV-GL, Det Norske Veritas-Germanischer Lloyd; API, American Petroleum Institute; ISO, International Organization for Standardization; HSE, Health and Safety Executive.

\begin{tabular}{|c|c|c|c|c|c|c|c|}
\hline Parameter & \multicolumn{2}{|c|}{ DNV GL-ST-0126 (2016) } & $\begin{array}{c}\text { DNV (2013) } \\
\text { Jackets/Single Pile }\end{array}$ & $\begin{array}{c}\text { NORSOK (2013) } \\
\text { Jackets }\end{array}$ & $\begin{array}{l}\text { API (2007) } \\
\text { Jackets }\end{array}$ & $\begin{array}{l}\text { ISO (2007) } \\
\text { Jackets }\end{array}$ & $\begin{array}{c}\text { HSE (2007) } \\
\text { Jackets }\end{array}$ \\
\hline$D_{\mathrm{p}} / t_{\mathrm{p}}$ & $20-60$ & $20-60$ & $10-60$ & $20-40$ & $\leq 40$ & $20-40$ & $24-40$ \\
\hline$D_{\mathrm{s}} / t_{\mathrm{s}}$ & $30-140$ & $18-140$ & $18-140$ & $30-140$ & $\leq 80$ & $30-140$ & $50-140$ \\
\hline$D_{\mathrm{g}} / t_{\mathrm{g}}$ & $10-45$ & I & 1 & $10-45$ & $7-45$ & $10-45$ & $10-45$ \\
\hline$t_{\mathrm{g}}$ & / & / & / & / & $\geq 38 \mathrm{~mm}$ & $\geq 40 \mathrm{~mm}$ & / \\
\hline$f_{\mathrm{cu}}(\mathrm{MPa})$ & / & / & / & $20-80$ & $17.25-110$ & $20-80$ & / \\
\hline$L_{\mathrm{g}} / D_{\mathrm{p}}$ & $1.0-10.0$ & $1.5-2.5$ & / & $1.0-10.0$ & 1 & $1.0-10.0$ & $\geq 2.0$ \\
\hline$h$ & $\geq 5 \mathrm{~mm}$ & $\geq 5 \mathrm{~mm}$ & / & $0-0.012 D_{\mathrm{p}}$ & / & $0-0.012 D_{\mathrm{p}}$ & $0-0.006 D_{\mathrm{p}}$ \\
\hline$s$ & $\geq 0.8 \sqrt{R_{p} t_{p}}$ & $\geq \sqrt{R_{p} t_{p}}$ & $\geq \sqrt{R_{p} t_{p}}$ & $\geq D_{\mathrm{p}} / 16$ & $\geq D_{\mathrm{p}} / 8$ & $\geq D_{\mathrm{p}} / 16$ & $\geq D_{\mathrm{p}} / 8$ \\
\hline$h / s$ & $\leq 0.1$ & $\leq 0.1$ & $\leq 0.1$ & $0-0.1$ & $0-0.1$ & $0-0.1$ & $\leq 0.04$ \\
\hline$w / h$ & $1.5-3.0$ & $1.5-3.0$ & / & / & $1.5-3.0$ & $1.5-3.0$ & $1.5-3.0$ \\
\hline
\end{tabular}

$L_{\mathrm{g}}$, length of grout; $f_{\mathrm{cu}}$, cubic compressive strength of grouted body.

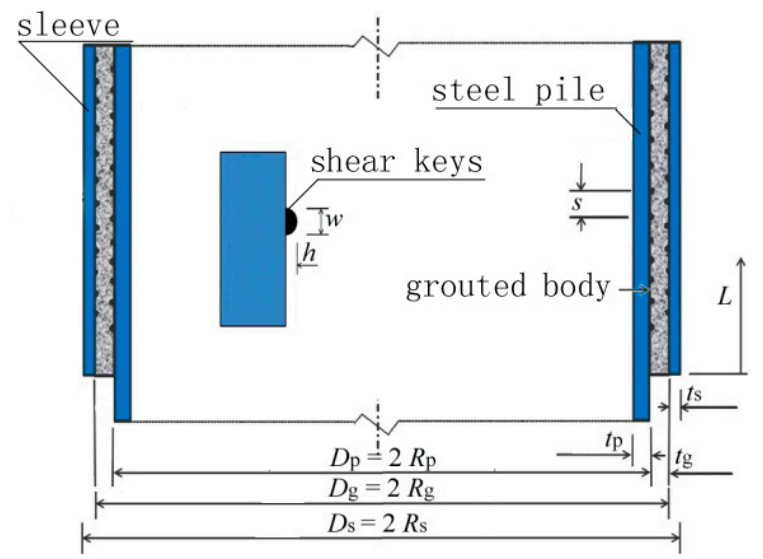

Figure 1. Geometric parameters of grouted connection. $D_{\mathrm{p}}$, diameter of steel pile; $D_{\mathrm{g}}$, diameter of grout; $D_{\mathrm{s}}$, diameter of sleeve; $R_{\mathrm{p}}$, radius of steel pile; $R_{g}$, radius of grout; $R_{s}$, radius of sleeve; $t_{p}$, thickness of steel pile; $t_{g}$, thickness of grout; $t_{s}$, thickness of sleeve; $w$, width of shear key; $h$, height of shear key; $s$, spacing of shear key.

\subsection{Method of Calculation}

DNV-GL follows the ISO and NORSOK shear strength calculation formulas for grouted connections. Therefore, the prediction methods of ISO and NORSOK will not be contrasted here. The HSE's calculation of shear strength $f_{\mathrm{bk}}$ of grouted connections considers the effects of radial stiffness, 
the length of the grouted seam, surface roughness, the dimensions of the shear key, and the cubic compressive strength of the grouted body; related formulas are shown as Equations (1) and (2)

$$
\begin{gathered}
f_{\mathrm{bk}}=C_{\mathrm{L}}\left(9 C_{\mathrm{S}}+1100 \frac{h}{\mathrm{~s}}\right) k f_{\mathrm{cu}}^{0.5} \\
k=\left(\frac{D_{\mathrm{p}}}{t_{\mathrm{p}}}+\frac{D_{\mathrm{s}}}{t_{\mathrm{s}}}\right)^{-1}+\frac{1}{\mathrm{~m}}\left(\frac{D_{\mathrm{g}}}{t_{\mathrm{g}}}\right)^{-1}
\end{gathered}
$$

where $\mathrm{k}$ is the radial stiffness coefficient; $f_{\mathrm{cu}}$ is the cubic compressive strength of the grouted body; $C_{\mathrm{S}}$ is the surface state coefficient, and $C_{S}=1.0$ when $h / s \geq 0.005 ; m$ is the ratio of Young's modulus for steel and for grout material, and $m=18$ can be used if the Young's modulus for grout material is not known. In the absence of geometric data of the steel tube and shear key, see Table 2 for $C_{\mathrm{L}}$ parameter values, where $L$ is the nominal length of the grouted connecting section. The parameter value between two data points in the table is calculated using the linear difference method.

Table 2. Values of parameter $C_{\mathrm{L}}$.

\begin{tabular}{ccccc}
\hline$L / D_{\mathrm{p}}$ & 2 & 4 & 8 & $\geq 12$ \\
\hline$C_{\mathrm{L}}$ & 1.0 & 0.9 & 0.8 & 0.7 \\
\hline
\end{tabular}

The API's calculation of shear strength $f_{\mathrm{bk}}$ of grouted connections considers the influence of grouted material strength, shear key height, and the space of the shear key. Krahl et al. considered the failure mechanism of the pressure bar near the shear key in the grouted connecting section, and through linear regression analysis of the collected experimental data, the formula of shear strength is as shown in Equation (3). In order to ensure a certain safety factor, the API adjusts Equation (3) and adopts Equation (4) for design

$$
\begin{gathered}
f_{\mathrm{bk}}=1.15+1.72 f_{\mathrm{cu}} \frac{h}{\mathrm{~s}} \\
f_{\mathrm{bk}}=0.184+0.67 f_{\mathrm{cu}} \frac{h}{\mathrm{~s}}
\end{gathered}
$$

In DNV, the friction coefficient between the steel and the grouted material is considered by using the semi-empirical Equation (5), and the contact pressure between them is transformed into interfacial shear friction force after the radial deformation of the grouted connection section.

$$
\begin{gathered}
f_{\mathrm{bk}}=\frac{\mu E}{F}\left(\frac{h}{21 s} f_{\mathrm{cu}}^{0.4} \sqrt{\frac{t_{\mathrm{p}}}{R_{\mathrm{p}}}}\right) \frac{s}{L_{\mathrm{g}}} N \\
F=\frac{R_{\mathrm{p}}}{t_{\mathrm{p}}}+\frac{E t_{\mathrm{g}}}{E_{\mathrm{g}} R_{\mathrm{p}}}+\frac{R_{\mathrm{s}}}{t_{\mathrm{s}}}
\end{gathered}
$$

Here, $L_{\mathrm{g}}$ is the length of the grouted connection section (mm); $\mu$ is the friction coefficient between the steel tube and the grouted material (0.6); $E_{\mathrm{g}}$ and $E$ are the elastic modulus of the steel tube and the grouted material, respectively; $F$ is the radial flexibility coefficient; and $N$ is the number of shear keys.

In DNV-GL, two failure modes were proposed to calculate the shear strength of the grouted connection: strength $f_{\mathrm{bk}}$, corresponding to the frictional sliding failure mode, and strength $f_{\mathrm{bkg}}$, determined by the failure of the grouted material itself, as expressed by Equations (7) and (8), respectively, in which $f_{\mathrm{bk}}$ should not be greater than $f_{\mathrm{bkg}}$,

$$
f_{\mathrm{bk}}=\left[\frac{800}{D_{\mathrm{p}}}+140\left(\frac{h}{s}\right)^{0.8}\right] k^{0.6} f_{\mathrm{cu}}^{0.3}
$$




$$
f_{\mathrm{bkg}}=\left(0.75-1.4 \frac{h}{s}\right) f_{\mathrm{cu}}^{0.5}
$$

\section{Comparison of Calculation Results}

The background is based on a jacket foundation of an offshore wind power project as the prototype, and the grouted connection section between the foundation and the piles is taken as the research object. The shear bond height $h$, the space of shear key $S$, the strength of the grouted material $f_{\mathrm{cu}}$, and the radial stiffness of the grouted connection section $k$ are changed in order to analyze the shear strength of the grouted connection. The main dimension information of specimens is as follows: $D_{\mathrm{s}}=2600 \mathrm{~mm}$, $t_{\mathrm{s}}=70 \mathrm{~mm}, D_{\mathrm{p}}=2270 \mathrm{~mm}, t_{\mathrm{p}}=55 \mathrm{~mm}, D_{\mathrm{g}}=2460 \mathrm{~mm}, t_{\mathrm{g}}=95 \mathrm{~mm}, L_{\mathrm{g}}=7000 \mathrm{~mm}, f_{\mathrm{cu}}=130 \mathrm{MPa}$, $E_{\mathrm{g}}=55 \mathrm{GPa}, E=206 \mathrm{GPa}, h=20 \mathrm{~mm}, w=40 \mathrm{~mm}, s=500 \mathrm{~mm}$ ( $E_{\mathrm{g}}$ : Young's modulus for grout material; $E$ : Young's modulus for steel).

\subsection{Space of Shear Key}

The relationship between shear strength $f_{\mathrm{bk}}$ calculated by different codes and the applicable space of shear key $s$ is shown in Figure 2, where a maximum value for $s$ is not specified by API, HSE, and DNV-GL. In this study, $s$ does not exceed $2 \mathrm{~m}$. It can be found from the figure that within the selected value range of $s$, shear strength $f_{\mathrm{bk}}$ calculated by HSE is the largest, followed by the calculated result of API, and the smallest is by DNV-GL. With increased $s$, the variation trend of shear strength obtained by different specifications is consistent. In the interval where $s$ is less than $800 \mathrm{~mm}$, the value of $s$ has a significant effect on shear strength. As $s$ increases, the calculated value of shear strength decreases rapidly, and the curve calculated by HSE is the most sensitive. After the value of $s$ continues to increase beyond $1000 \mathrm{~mm}$, shear strength $f_{\text {bk }}$ of the grouted connection slowly decreases, and the curve calculated by each code gradually flattens. Since the DNV calculation result is fixed, it is considered that the shear strength of the grouted joint is not related to the space of the shear key, which is inconsistent with Wimpey's experimental phenomenon [16]. The Wimpey laboratory tested specimens with different shear key distances. The results showed that the shear strength of the grouted connections increased continuously when the space of the shear key s continued to decrease. However, as $s$ was reduced to a certain extent, the failure mode of the grouted joint changed, and the shear strength of the grouted section decreased.

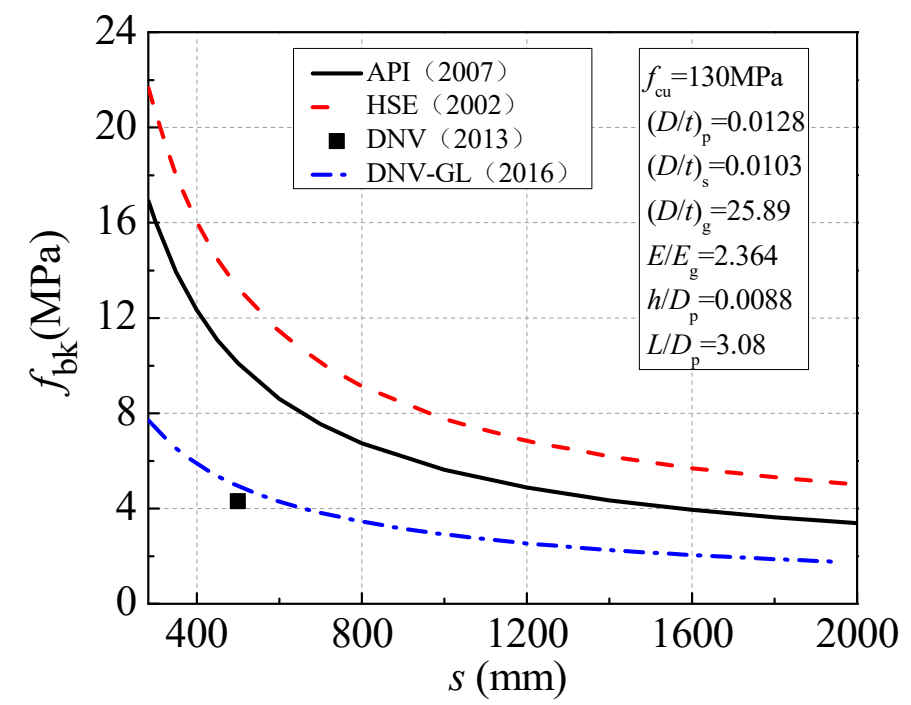

Figure 2. Relationship between interface shear strength $\left(f_{\mathrm{bk}}\right)$ and shear key distance $(s)$. 


\subsection{Height of Shear Key}

Shear key height $h$ has a leading influence on shear strength $f_{\mathrm{bk}}$ of the grouted joint. When the minimum value of $h$ is taken, it means there is no shear key on the grouted joint, and the maximum value of $h$ is generally half the thickness of the grouted material, which is generally greater than the value in an actual project. The curve of shear strength $f_{\mathrm{bk}}$ calculated by different codes and shear key height $h$ is shown in Figure 3, where the specifications of API, DNV, and DNV-GL do not set a maximum value of $h$, and only the case when $h$ less than $50 \mathrm{~mm}$ is compared. It can be seen from the data that the DNV takes $f_{\mathrm{bk}}$ as 0 , when $h=0$, ignoring the cohesive force and friction force between grouted material and the steel pipe surface. With increased $h$, the slope of the HSE curve becomes the largest and $f_{\text {bk }}$ grows the fastest. However, the application scope of $h$ in HSE is limited. Compared with DNV and DNV-GL, the API curve increases faster with increased $h$, reflecting that the influence of $h$ becomes more obvious. The DNV-GL code requires that the height of shear key $h$ is greater than $5 \mathrm{~mm}$, to avoid slippage damage on the interface of steel pipe and grouted material in the grouted section. The slope of the curve of the DNV code is the smallest, and shear strength $f_{\mathrm{bk}}$ of the calculation is the smallest with increased $h$. In addition, the API, DNV, and DNV-GL codes assume that shear strength $f_{\mathrm{bk}}$ will continue to increase with the growth of $h$, which disagrees with the actual situation.

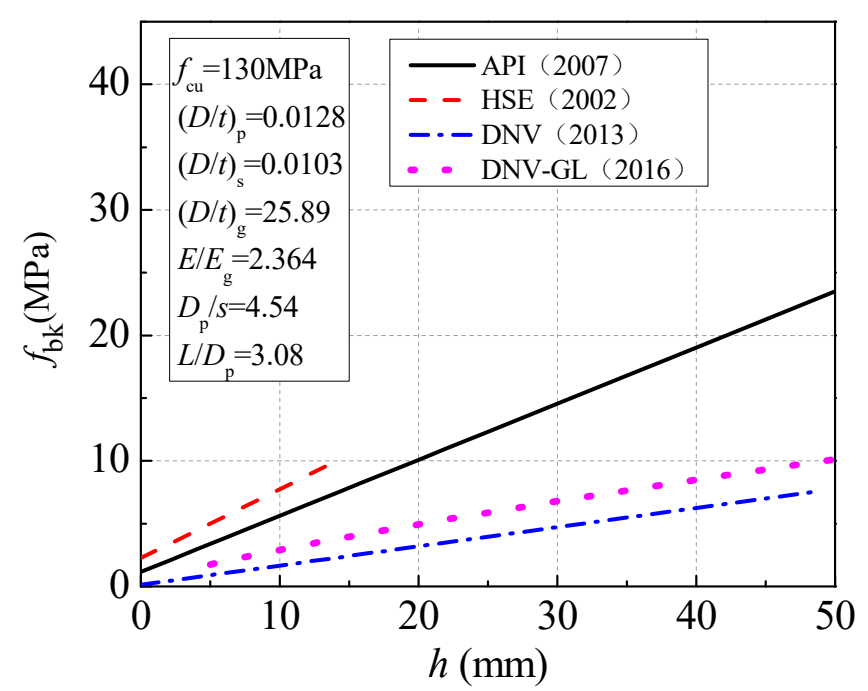

Figure 3. Relationship between interface shear strength $\left(f_{\mathrm{bk}}\right)$ and shear key height $(h)$.

\subsection{Ratio of Height to Distance of Shear Key}

Forsyth et al. [17] considered that $h / s$ has an optimal value, which corresponds to the maximum shear strength $f_{\mathrm{bk}}$ of a grouted connection. The relationship curve of shear strength $f_{\mathrm{bk}}$ calculated by different codes and the $h / s$ ratio are shown in Figure 4 . It can be concluded that the slope of the HSE curve is the largest, and with increased $h / s$ ratio, the growth rate of $f_{b k}$ is the largest, but $h / s$ in HSE is less applicable. However, the application scope of the $h / s$ ratio in the HSE code is relatively low. When a large $h / s$ ratio is required in the test, the HSE code is inapplicable. The curves of the API, DNV, and DNV-GL codes generally show a linear growth trend. When the $h / s$ ratio is large, the API calculation value is the largest, while the DNV counterpart is the smallest. The maximum $h / s$ ratio applicable to the specification is 0.1 . 


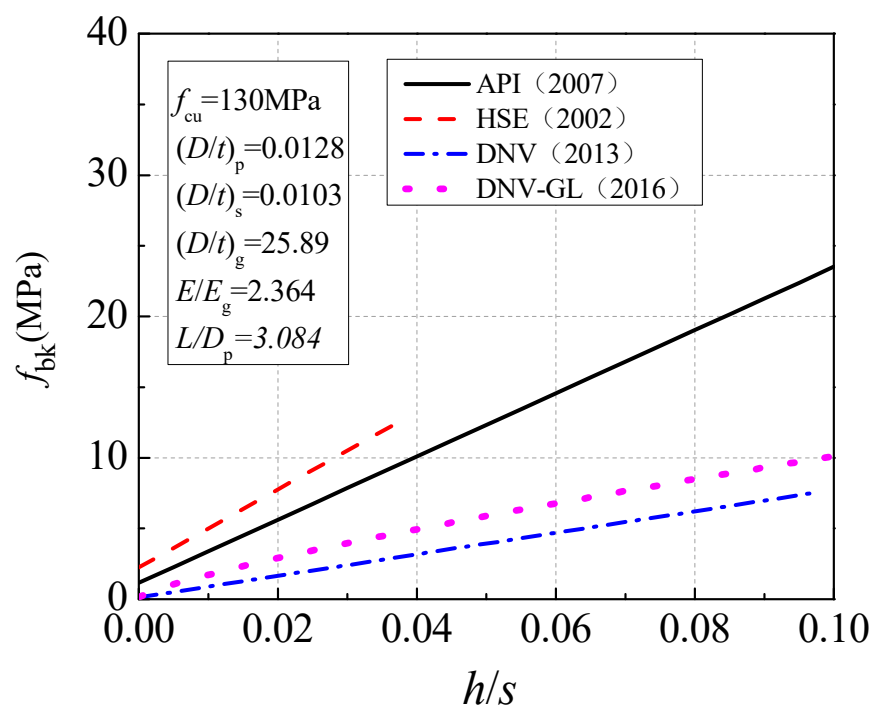

Figure 4. Relationship between interface shear strength $\left(f_{\mathrm{bk}}\right)$ and height-to-distance ratio of shear key $(h / s)$.

\subsection{Compressive Strength of Grouted Material}

The failure mode of the grouted joint with moderate distance of the shear key indicates that the grouted material at the shear bond position is crushed with the slip between the steel pipe and the grouted body, and $f_{\mathrm{cu}}$ plays a significant role in $f_{\mathrm{bk}}$. Billington showed through data analysis that $f_{\mathrm{bk}}$ is directly proportional to the 0.5 power of $f_{\mathrm{cu}}$ [9]. The relationship curve between the shear strength $f_{\text {bk }}$ calculated using different codes and the compressive strength of grouted material $f_{c u}$ is shown in Figure 5. It can be found that API considers that $f_{\mathrm{bk}}$ and $f_{\mathrm{cu}}$ show a linear relationship, which is not consistent with the results of Billington's analysis. API overestimates the effect of $f_{\mathrm{cu}}$ on $f_{\mathrm{bk}}$, and $f_{\mathrm{cu}}$ is less applicable in the API code. When the compressive strength of larger or smaller grouted materials is used in the test, the formula in the API code is not necessarily applicable. In contrast, HSE, DNV, and DNV-GL agree that the ultimate shear strength of the grouted junction is proportional to the 0.5 , 0.4 , and 0.3 power cubic compressive strength of the grouted material, and the DNV code is constantly reducing the impact of $f_{\mathrm{cu}}$ on $f_{\mathrm{bk}}$.

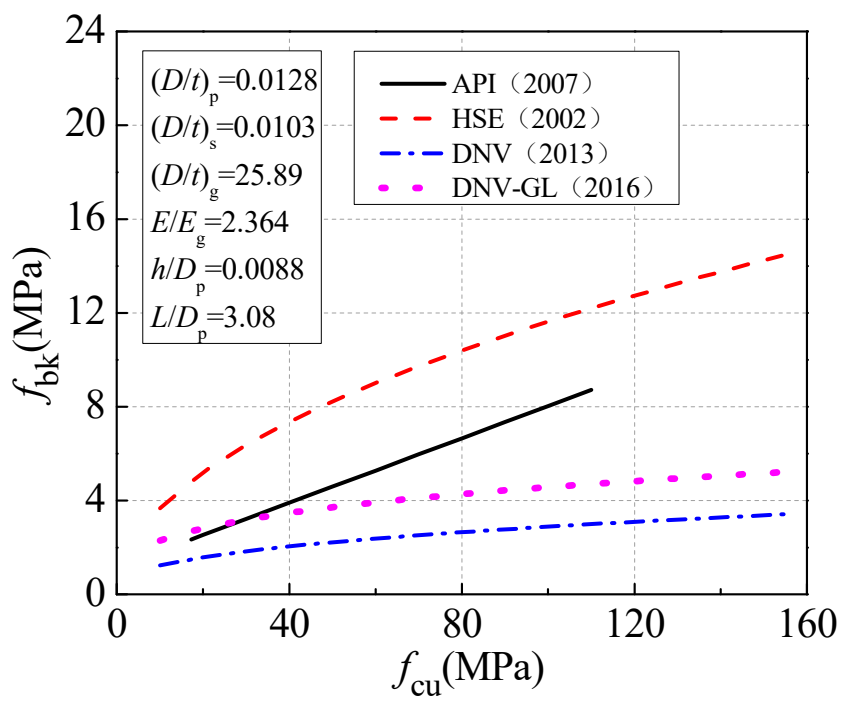

Figure 5. Relationship between interface shear strength $\left(f_{\mathrm{bk}}\right)$ and grouted material strength $\left(f_{\mathrm{cu}}\right)$. 


\subsection{Radial Stiffness Coefficient}

Due to the irregular surface of the steel pipe and the grouted material, any slip between them will cause radial deformation of the inner and outer steel pipes and the grouted material. Increased pressure between the contact surface of the steel pipe and the grouted material increases the friction between the contact surfaces, which will lead to improved axial strength of the grouted connection. Therefore, radial stiffness coefficient $K$ has a more significant influence on the grouted connection. The test results of Aritenang [18] confirmed a similar view, that increased radial stiffness can help to improve the axial strength of grouted connections. The relationship between $f_{\mathrm{bk}}$ obtained by different codes and radial stiffness $\mathrm{K}$ is shown in Figure 6. It can be concluded that the API code holds that there is no direct relationship between $f_{\mathrm{bk}}$ and $K$, that is, the change of radial stiffness of the grouted connection section will not affect the shear strength of the grouted joint. In contrast, the HSE and DNV codes assume that $f_{\mathrm{bk}}$ of the grouted junction is proportional to radial stiffness $K$. The DNV-GL code assumes that $f_{\mathrm{bk}}$ is proportional to the 0.6 power of radial stiffness coefficient $K$, which reduces the effect of $K$ on the shear strength of the grouted connection.

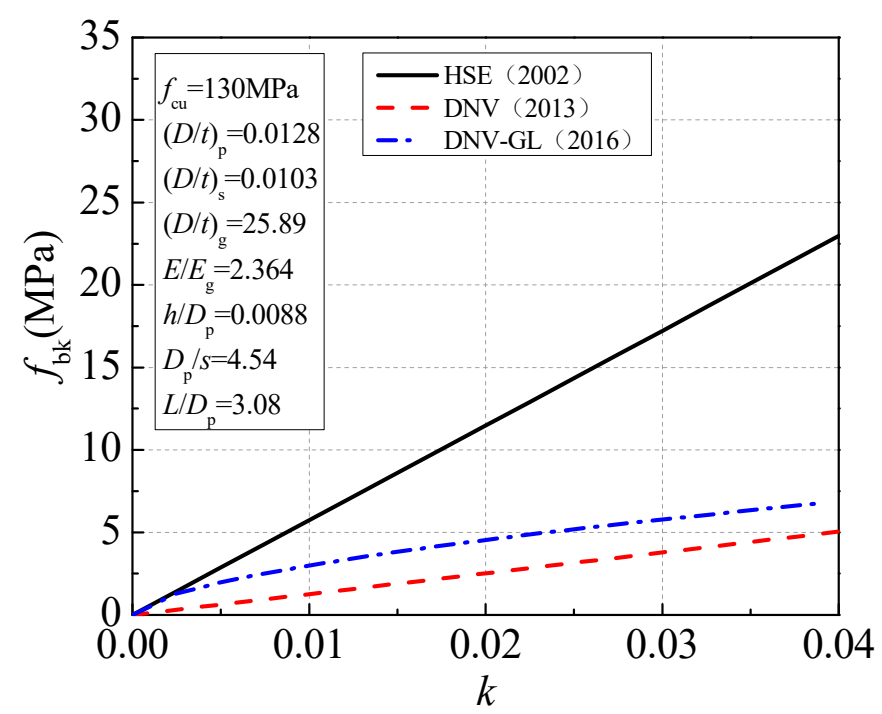

Figure 6. Relationship between $f_{\mathrm{bk}}$ and radial stiffness factor $(k)$.

Formulas in the DNV-GL and HSE codes adopt the same radial stiffness $K$, and believe that it is related to the diameter-to-thickness ratio of steel pipe pile $D_{\mathrm{p}} / t_{\mathrm{p}}$, the diameter-to-thickness ratio of steel sleeve $D_{\mathrm{s}} / t_{\mathrm{s}}$, the $D_{\mathrm{g}} / t_{\mathrm{g}}$ ratio, and the ratio of elastic modulus of steel pipe to grouted material $E / E_{\mathrm{g}}$. Hence, the analysis results of radial stiffness $K$ are presented in Figure 7 by changing the parameters above. It can be found that a $D_{\mathrm{g}} / t_{\mathrm{g}}$ ratio between 0 and 15 shows a significant effect on radial stiffness $K$, but this effect gradually decreases when the ratio is more than 15 . The $D_{\mathrm{p}} / t_{\mathrm{p}}$ and $D_{\mathrm{s}} / t_{\mathrm{S}}$ ratios have less effect on radial stiffness $K$. The $E / E_{\mathrm{g}}$ ratio can only achieve a relatively small change range because the value only relates to the material properties, but it can also effectively enhance radial stiffness $K$ in the variation range. 


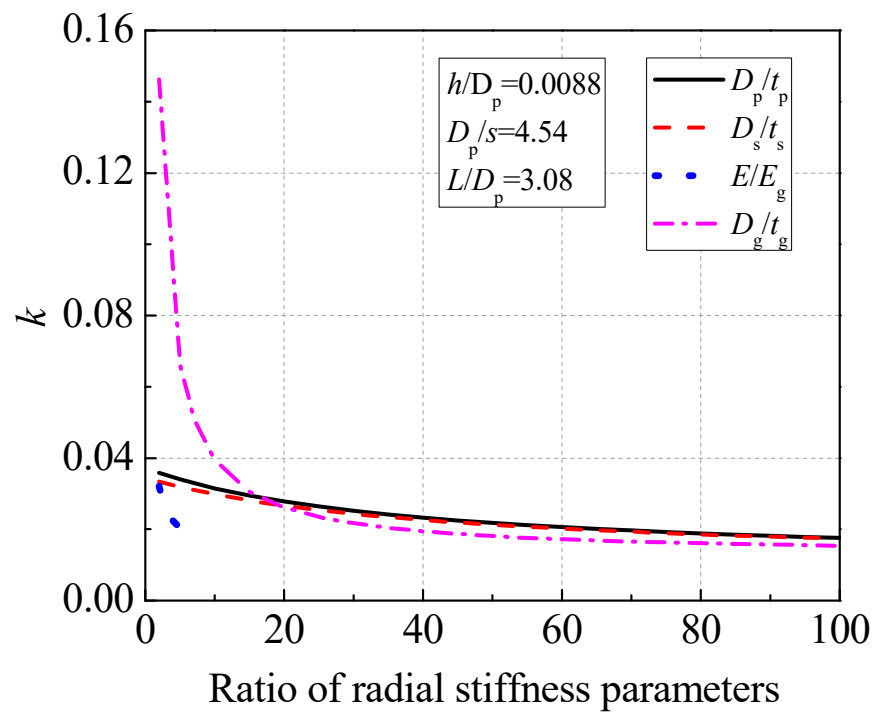

Figure 7. Relationship between radial stiffness factor $(k)$ and $D_{\mathrm{p}} / t_{\mathrm{p}}, D_{\mathrm{s}} / t_{\mathrm{s}}, E / E_{\mathrm{g}}$, and $D_{\mathrm{g}} / t_{\mathrm{g}}$ ratios.

\section{Comparison between Calculation and Test Results}

\subsection{Data Acquisition and Verification}

In order to further study the accuracy and effectiveness of the formula in different codes, the axial test results of 270 grouted connections with shear keys were collected in the study [8,16-25]. Then the code calculation process was applied to compare the results with the experimental ones.

However, due to the incomplete information of some specimens given in the documents, only 64 sets of test data were available for analysis; 13 sets involving specimens that did not meet the application range of DNV-GL were excluded, and the data of the remaining 51 sets of specimens could be calculated, analyzed, and compared. In order to ensure the reliability of the collected data, the verification work was carried out by the axial compression test and finite element analysis of grouted connections. A total of seven grouted-connection specimens were tested. The specimen dimensions are shown in Table 3 . A 10,000 kN electro-hydraulic servo-controlled long column pressure tester was employed to apply uniform loading under the control of a computer. The loading equipment and monitoring points are shown in Figures 8 and 9. Displacement was measured using displacement transducers (DTs), and the DT arrangements in specimens are illustrated in Figure 10a. DA1 and DA2 were adsorbed on the outer surface of the outer tube by the magnetic base, and were used to measure the relative vertical displacement of the inner and outer tubes during the test; DB1 was used to measure the overall displacement of the lower end plate of the test machine; and DB2 was used to measure the vertical displacement of the upper bearing plate. Strain gauges were glued to the outer surface of the outer tube and inner surface of the inner tube. The positions and coordinates of the strain gauges for specimens are presented in Figure 10b. The positions of the strain gauges on the outer surface of the outer tube corresponded to the positions of the shear keys on the inner surface of the outer tube; four groups of strain gauges were symmetrically arranged on each shear key; each group of strain gauges included one longitudinal and one circumferential strain gauge, which were used to test the longitudinal and circumferential strain of the steel tube during the test loading process. The positions of the strain gauges on the inner surface of the inner tube corresponded to the positions of the shear keys on the outer surface of the inner tube; two groups of strain gauges were symmetrically arranged on each shear key; each group of strain gauges included one longitudinal strain gauge, which was used to test the longitudinal strain of the inner tube during the test loading. In order to protect the strain gauges glued to the inner surface of the inner tube from damage during grouting and curing, their surface was coated with epoxy resin. 
Table 3. Dimensions of test specimens.

\begin{tabular}{ccccccccc}
\hline No. & $\boldsymbol{D}_{\mathbf{s}} \mathbf{( \mathbf { m m } )}$ & $\boldsymbol{t}_{\mathbf{s}} \mathbf{( \mathbf { m m } )}$ & $\boldsymbol{D}_{\mathbf{p}} \mathbf{( \mathbf { m m } )}$ & $\boldsymbol{t}_{\mathbf{p}} \mathbf{( \mathbf { m m } )}$ & $\boldsymbol{L}_{\mathbf{g}}(\mathbf{m m})$ & $\boldsymbol{h} \mathbf{( \mathbf { m m } )}$ & $\boldsymbol{W}(\mathbf{m m})$ & $\boldsymbol{s}(\mathbf{m m})$ \\
\hline GC-N2 & 600 & 12 & 480 & 12 & 350 & 5 & 10 & 75 \\
GC-S75 & 600 & 12 & 480 & 12 & 500 & 5 & 10 & 75 \\
GC-S50 & 600 & 12 & 480 & 12 & 400 & 5 & 10 & 50 \\
GC-S100 & 600 & 12 & 480 & 12 & 600 & 5 & 10 & 100 \\
GC-H2.5 & 600 & 12 & 480 & 12 & 500 & 2.5 & 5 & 75 \\
GC-T38 & 580 & 12 & 480 & 12 & 500 & 5 & 10 & 75 \\
GC-T63 & 630 & 12 & 480 & 12 & 500 & 5 & 10 & 75 \\
\hline
\end{tabular}

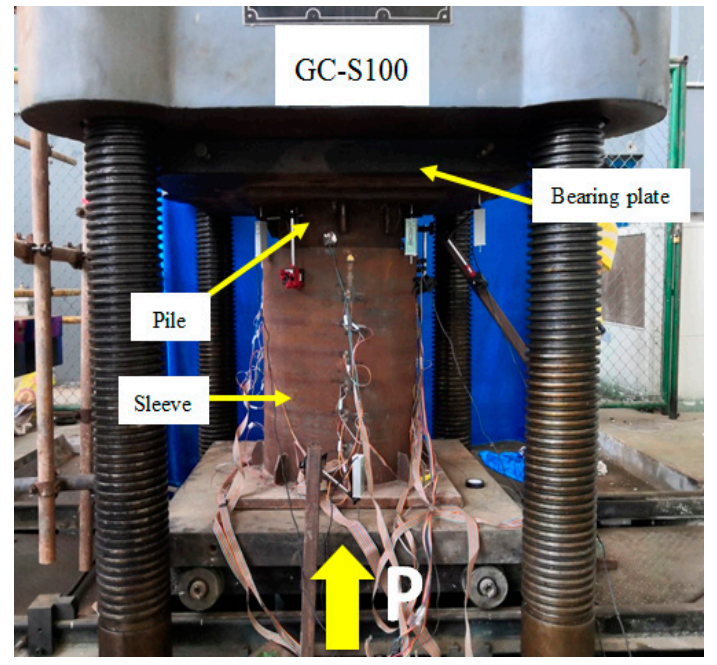

Figure 8. Schematic diagram of specimen loading in grouted connection.

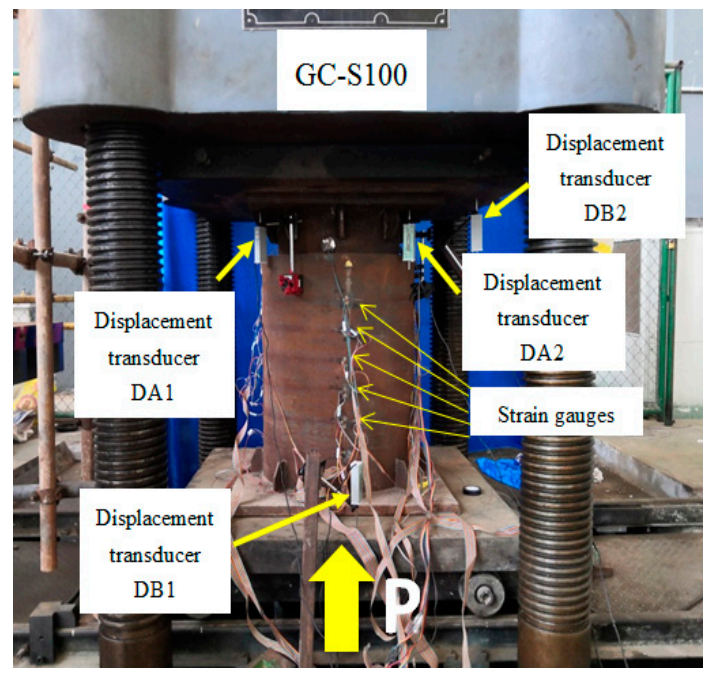

Figure 9. Schematic diagram of test points arrangement of grouted connection. 


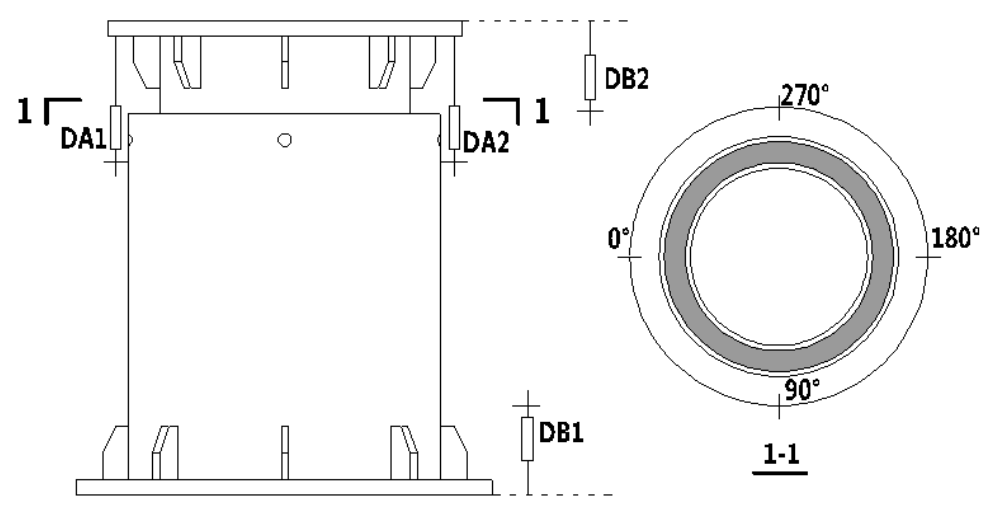

(a)
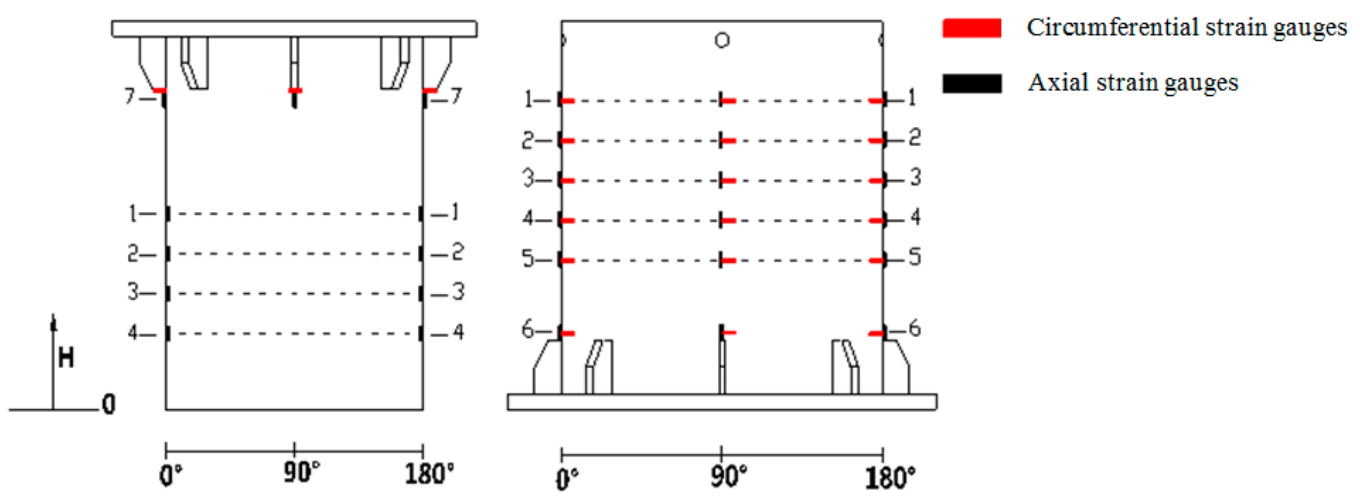

(b)

Figure 10. Arrangement of (a) displacement transducers (DTs) and (b) strain gauges on specimens.

Abaqus was selected for finite element simulation analysis. It is particularly significant to select the appropriate material models of compression and tensile properties of the grouting body. Given that the grouting material is a nonlinear brittle material, the concrete damage plastic (CDP) model was chosen for the simulation, which can effectively reflect the main failure mechanism of the brittle material. The basic model parameters of the material are shown in Table 4. For the steel, the elastoplastic material model based on classic metal plasticity theory was adopted in Abaqus. The von Mises yield criterion and kinematic hardening theory were used. The elastoplastic strengthening model of the ideal double-fold line was adopted for the constitutive relationship of the steel in this paper.

Table 4. Material properties.

\begin{tabular}{ccccc}
\hline Material & $\begin{array}{c}\text { Young's } \\
\text { Modulus (MPa) }\end{array}$ & $\begin{array}{c}\text { Yield Strength } \\
\text { (MPa) }\end{array}$ & $\begin{array}{c}\text { Ultimate } \\
\text { Strength (MPa) }\end{array}$ & Poisson's Ratio \\
\hline Steel & $2.06 \times 10^{5}$ & 380 & 565 & 0.31 \\
Grout (GC-S75) & $5.1 \times 10^{4}$ & $/$ & 149.1 & 0.2 \\
Grout (GC-S50) & $5.1 \times 10^{4}$ & $/$ & 149.3 & 0.2 \\
Grout (GC-S100) & $5.1 \times 10^{4}$ & $/$ & 154.2 & 0.2 \\
Grout (GC-H2.5) & $5.1 \times 10^{4}$ & $/$ & 150.2 & 0.2 \\
Grout (GC-N2) & $5.1 \times 10^{4}$ & $/$ & 131.2 & 0.2 \\
Grout (GC-T38) & $5.1 \times 10^{4}$ & $/$ & 150.2 & 0.2 \\
Grout (GC-T63) & $5.1 \times 10^{4}$ & $/$ & 150.3 & 0.2 \\
\hline
\end{tabular}


The outer casing tube, steel pipe pile, and grouting section of the grouting connection were modeled with 3D solids, and the unit was an eight-node hexahedral linear reduction integration unit (C3D8R). The modeling method was the axisymmetric semi-structural method. The contact setting included the contact of the steel casing with the grouting material and the contact of the grouting material with the steel pipe pile. Surface contact was established between the grouting material and the inner wall of the steel casing and the outer wall of the steel pipe pile. Between the grout and the steel pipe interface, a contact pair was set up for face-to-face contact. The contact in the normal direction was set as a hard contact, and a Coulomb friction model with a penalty function was used in the tangential direction. The model friction coefficient was taken as 0.4 .

A fixed constraint was imposed on the top surface of the steel pipe pile. Due to the use of axisymmetric semi-structure modeling, the symmetry constraint was imposed on the axisymmetric cross-section of the grouting connection specimen. The center of the axis of symmetry of the steel casing was selected to set a reference point, the reference point was coupled to the bottom surface of the outer sleeve, and a displacement load was applied to this reference point. The model boundary conditions are shown in Figure 11.
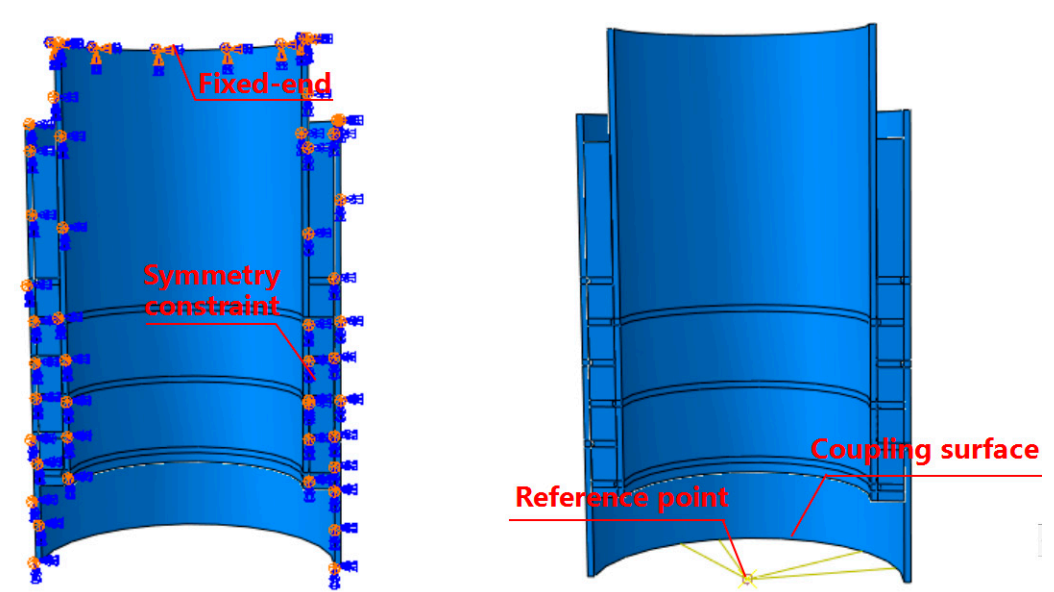

Figure 11. Model boundary conditions.

The test results were fitted by continuously adjusting the characteristic parameters of the finite element model, focusing on the load-displacement curve and failure mode as the data fitting target. A comparison table of the ultimate strength (Table 5), a comparison diagram of the load-displacement curve (Figure 12), and a comparison diagram of the final failure mode (Figure 13) were obtained after the fitting study. The calculated results of the fitted finite element model agree with the test results. The main factors affecting the finite element model are the material model parameters of the grout. The values of specific parameters are shown in Table 6.

Table 5. Comparison of peak loads.

\begin{tabular}{cccccccc}
\hline No. & GC-S75 & GC-S50 & GC-S100 & GC-H2.5 & GC-N2 & GC-T38 & GC-T63 \\
\hline $\mathrm{P}_{\text {TEST }}$ & 5887 & 5204 & 7196 & 4683 & 2437 & 5843 & 5753 \\
$\mathrm{P}_{\text {FEA }}$ & 6127 & 5481 & 6954 & 4712 & 2563 & 6315 & 6251 \\
Error & $4 \%$ & $5 \%$ & $-3 \%$ & $1 \%$ & $5 \%$ & $8 \%$ & $9 \%$ \\
\hline
\end{tabular}

$\mathrm{P}_{\mathrm{TEST}}$ is the experimental peak load; $\mathrm{P}_{\mathrm{FEA}}$ is the numerical peak load. 


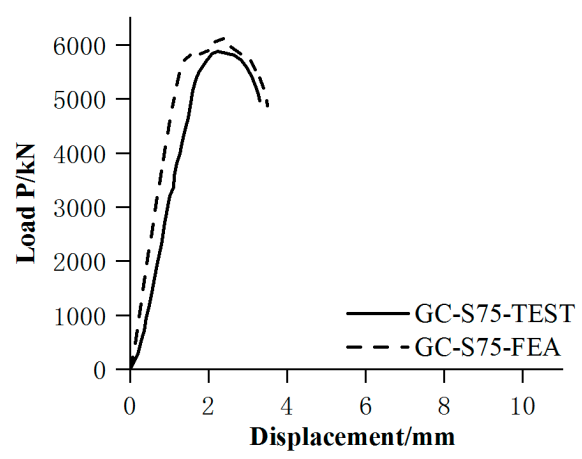

(a)

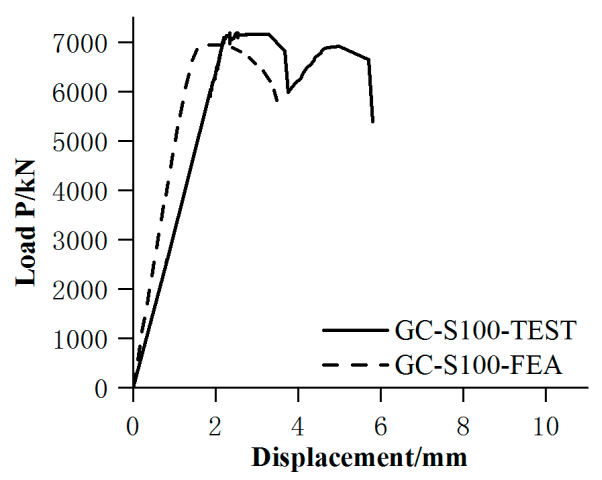

(c)

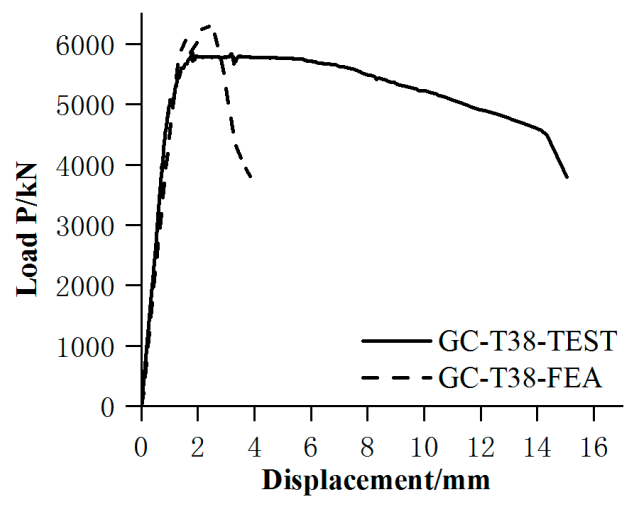

(e)

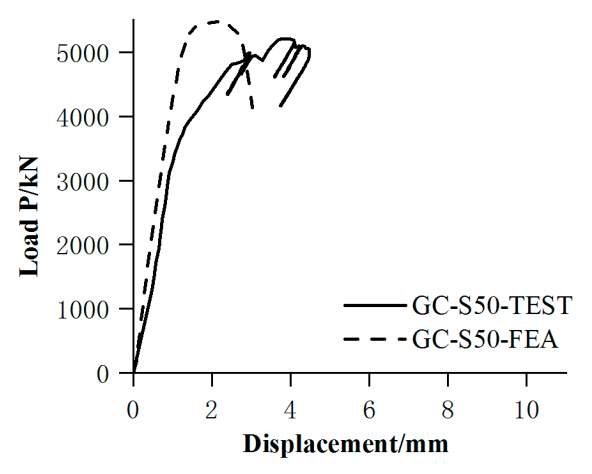

(b)

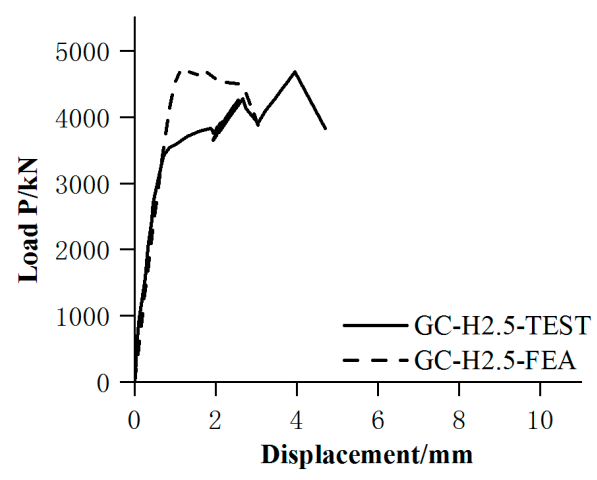

(d)

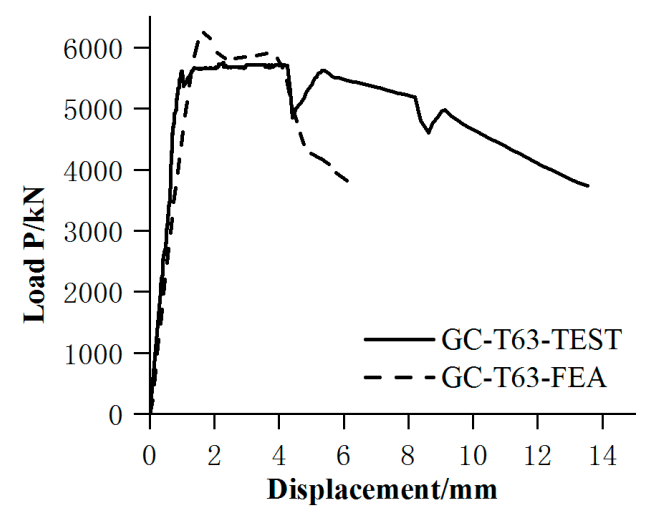

(f)

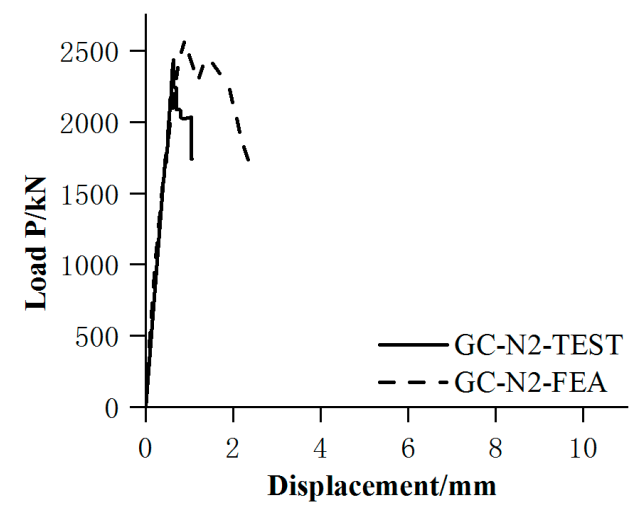

(g)

Figure 12. Comparison of test load-displacement curves: (a) S75; (b) S50; (c) S100; (d) H2.5; (e) T38; (f) $\mathrm{T} 63 ;(\mathrm{g}) \mathrm{N} 2$. 

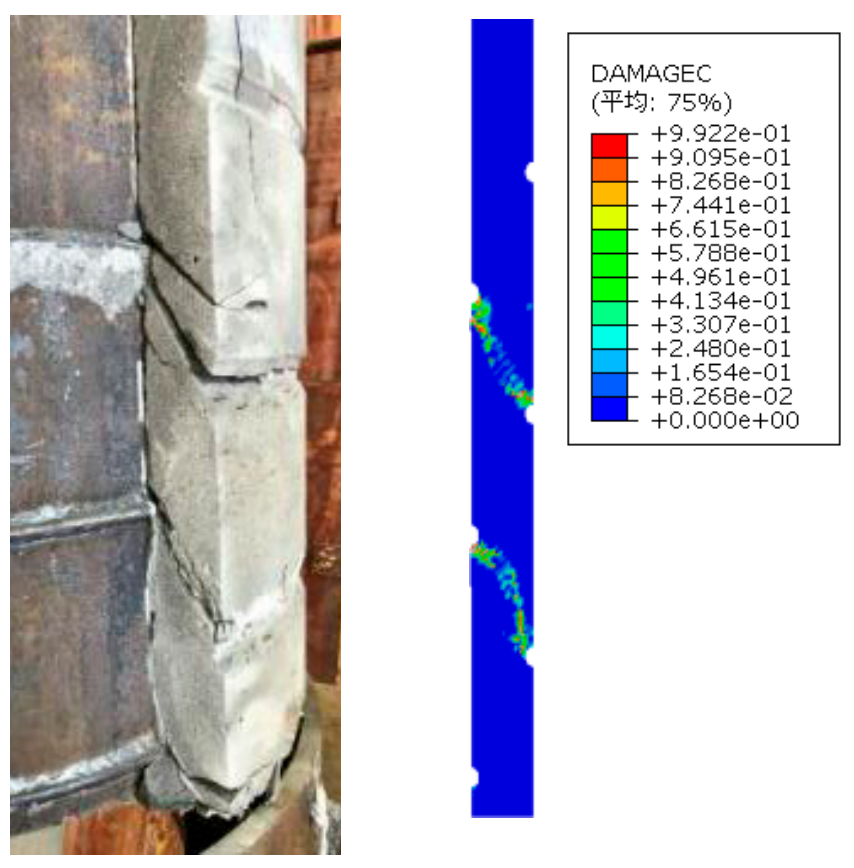

Figure 13. Comparison of failure modes.

Table 6. Grout parameters.

\begin{tabular}{ccccc}
\hline$\psi$ & $K_{\mathrm{c}}$ & $\alpha_{\mathrm{f}}$ & $\varepsilon$ & $\mu$ \\
\hline 30 & $2 / 3$ & 1.16 & 0.1 & 0.0001
\end{tabular}

$\psi$ is the dilation angle; $K_{\mathrm{c}}$ is the second stress invariant; $\alpha_{\mathrm{f}}$ is the biaxial/uniaxial ratio; $\varepsilon$ is the eccentricity; $\mu$ is the viscosity parameter.

A finite element analysis of 51 specimens in the database was performed using the fitted model parameters obtained from the experiments. The results show that the experimental results for most of the specimens and the finite element calculation results basically match, thus the validity of the database data can be determined. In addition, a database of 58 samples was obtained incorporating the seven test results in this paper. A comparison between the calculation results of the above prediction methods and the database data was conducted.

\subsection{HSE (2002)}

The shear strength of the specimens obtained from the HSE code was compared with the test results in Figure 14. It can be concluded that the HSE calculation results are more discrete than the test results, and the maximum deviation ratio is $196 \%$. Only 15 of the 51 specimens have a deviation ratio less than $10 \%$, and there are 14 specimens out of the remaining 36 with deviation ratios exceeding 10\% whose calculation results are higher than the test results. In general, although the HSE formula has some feasibility, the result is quite discrete. In most cases, the HSE formula overestimates the shear strength of grouted connections, presenting certain security risks. 


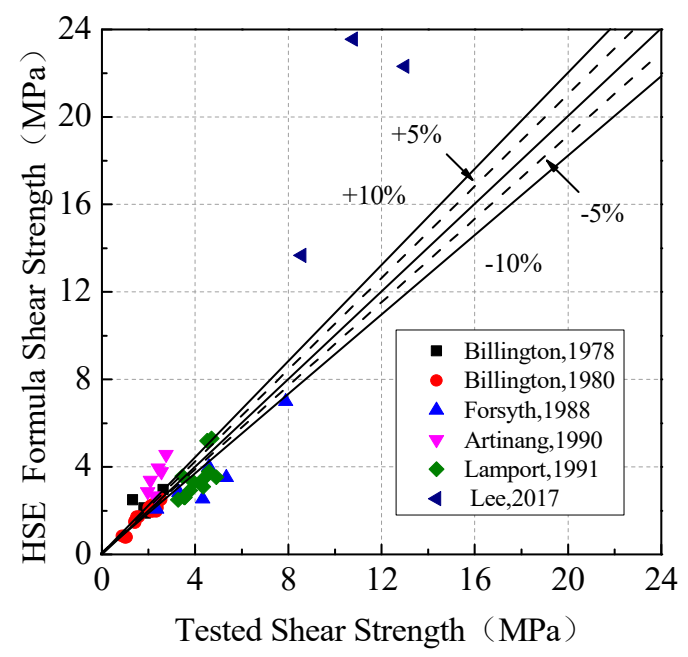

Figure 14. Comparison of shear strength calculated using HSE and tested results.

\subsection{API (2007)}

The API specification considers that the shear strength of the grouted connection under axial load is only linearly related to the product of grouted material strength and the shear key height-to-distance ratio, $h / s$. Irrespective of the radial stiffness of the grouted connection, the corresponding design formula is obtained by linear regression with the safety factor added. A comparison between the regression formula calculation results and the test results is shown in Figure 15a. The formula fitted by the API code is representative, regardless of the value of shear strength. It can be used to predict and evaluate the axial strength in the absence of geometric parameters of grouted connections. However, the difference between the calculated value from the formula and the experimental value is obvious. Only 2 out of 51 specimens have a deviation ratio of less than $10 \%$, and the maximum deviation ratio is $168 \%$. A comparison between the calculated results obtained from the revised design formula and the test results is shown in Figure 15b. All the scattered points are distributed under the diagonal line, and the shear strength calculated by the formula is less than the test values; especially when the strength is high, the design formula is conservative.

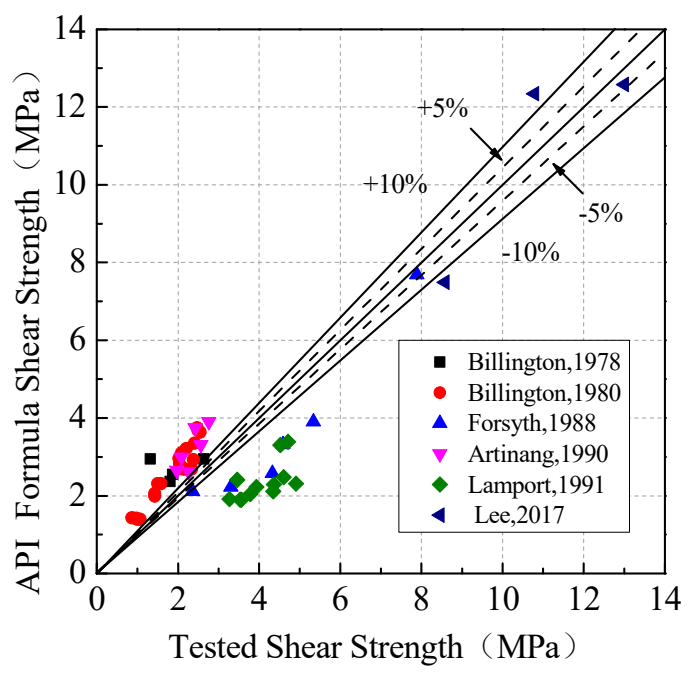

(a)

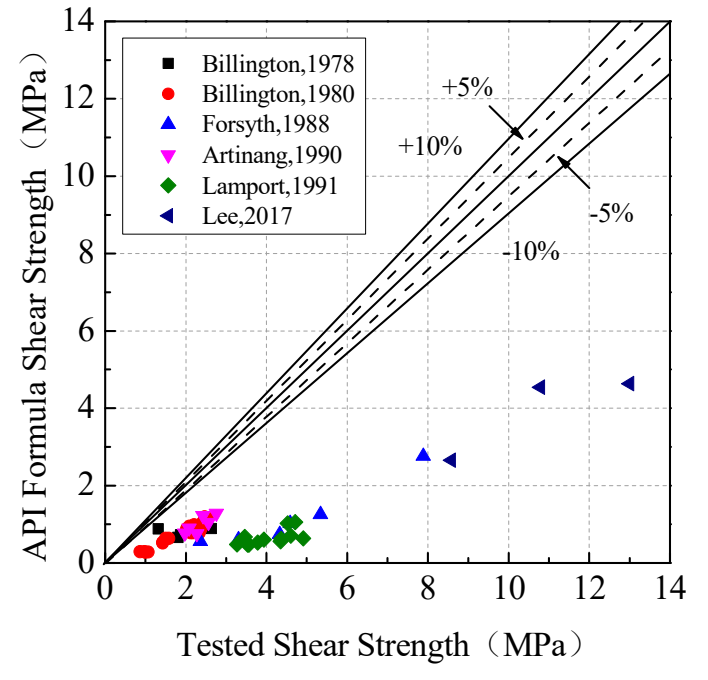

(b)

Figure 15. Comparison of shear strength calculated using API and tested results: (a) API fitting formula; (b) formula under extreme conditions. 


\section{4. $D N V(2013)$}

Figure 16 shows a comparison between the shear strength calculated by the DNV code and the test results. The difference between the DNV code and experimental results is still quite discrete. The shear strength of some specimens is seriously overvalued, and a few calculated values are nearly three times higher than the test results. Overestimated strength results in 12 specimens with a deviation ratio exceeding $10 \%$, and there are also 33 specimens whose strength is undervalued with a deviation ratio exceeding $10 \%$. For the most part, the DNV code specification may lead to unsafe design results.

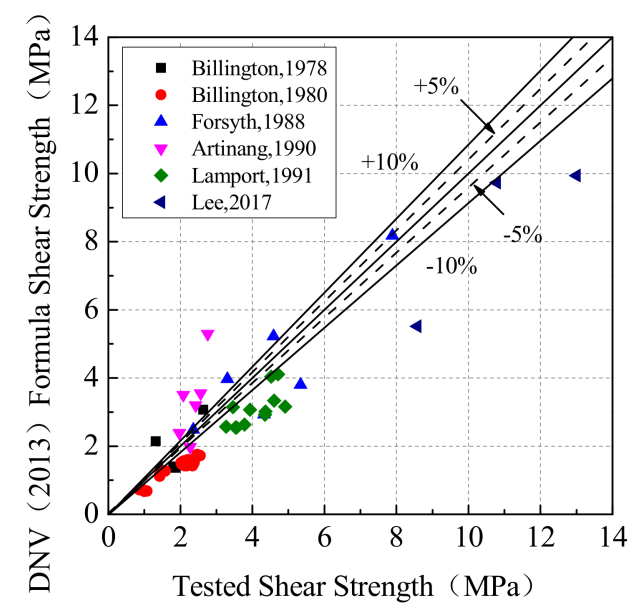

Figure 16. Comparison of shear strength calculated using DNV and tested results.

\subsection{DNV-GL (2016)}

The shear strength of specimens calculated by the DNV-GL code were compared with the test results, as shown in Figure 17. It can be seen that the DNV-GL code had better applicability when the shear strength in the test was below $3 \mathrm{MPa}$; only two specimens have a calculated value $10 \%$ higher, which indicates the reliability of this code for predicting the axial strength of grouted joints. However, as the shear strength of the specimen increased, the calculation result became smaller; 36 out of the 51 specimens have test results that are more than $10 \%$ above the calculation result. It can be considered that the DNV-GL code has excellent applicability when the shear strength of the grouted joint is relatively low, and it also can guarantee safety when the shear strength is high.

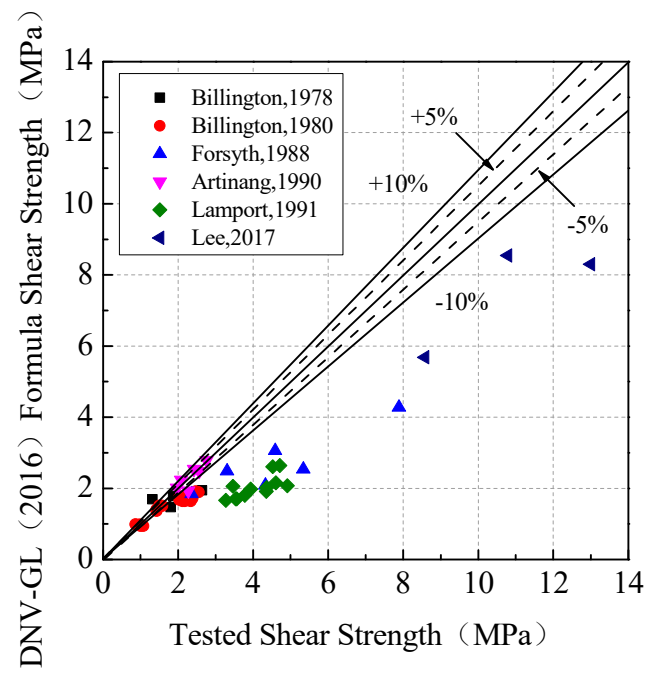

Figure 17. Comparison of shear strength calculated using DNV-GL and tested results. 


\section{Conclusions}

The distinctions between shear strength calculated by different codes for the same grouted connection are presented in this paper. The overall calculation result from the API (2007) code is the lowest, followed by DNV GL (2016), and HSE (2002) is the highest. According to the analysis results, the prediction method of DNV GL (2016) is reasonable, that of API is the most conservative, and that of HSE is the most radical, which is unsafe from the perspective of design.

Compared with the experimental results, the theoretical results of different codes are significantly different, generally more than $10 \%$. The prediction method of axial strength of grouted connections still needs further research. At present, the results of grouted connection strength in the standards still have certain limitations, mainly because the test results are not rich enough, so there is still a lot of research work to be carried out. Moreover, the research work cannot be confined to static structures; ocean engineering must also pay attention to structure fatigue performance.

The calculation formula from HSE (2002) has obvious limitations due to the obvious simple superimposing effect, especially in the case of long grouted connections and great numbers of shear keys, so the strength is often overestimated, resulting in insecure design outcome of structures. By contrast, when there are fewer shear keys, good applicability can be guaranteed. The reliability of the calculation formula from DNV (2013) has been improved in terms of more shear keys. However, the calculated results by DNV (2013) deviate from actual capacity in some parameter combinations, which may lead to serious overestimation of the strength of specimens.

In the absence of specific parameters of specimens, the fitting formula in the API (2007) code can credibly predict the axial strength of grouted joints. However, the formula seriously undervalues the bearing performance of grouted joints, leading to relatively uneconomic design results. The formula in the DNV-GL (2016) code for axial strength of grouted joints is safe and reliable. In some cases, the axial strength calculated by DNV-GL (2016) may undervalue the actual capacity, but its prediction method has wider applicability, which is safe, reliable, and economical in the current situation.

Author Contributions: Conceptualization, Y.X. and W.Z.; Investigation, Y.X., C.Z., and W.Z.; Data curation, Y.X. and C.Z.; Conceived and designed the experiments, Y.X. and W.Z.; Performed the experiments, C.Z. and Y.X.; Analyzed the data, Y.X. and C.Z.; Contributed reagents/materials/analysis tools, W.Z.; Writing, Y.X. All authors have read and agreed to the published version of the manuscript.

Funding: This research was funded by the Natural Science Foundation of Fujian Province of China grant number 2017J01697.

Acknowledgments: This research was supported financially by the China Three Gorges Corporation and China Fujian Provincial Department of Science and Technology of China, which are gratefully acknowledged. The authors would also like to acknowledge Fujian Provincial Key Laboratory on Multi-Disasters Prevention and Mitigation in Civil Engineering, for laboratory help.

Conflicts of Interest: The authors declare no conflict of interest.

\section{References}

1. The European Wind Energy Association. The European Offshore Wind Industry Key Trends and Statistics; EWEA: Brussels, Belgium, 2010-2013.

2. HSE. Pile/Sleeve Connections; Health \& Safety Executive (HSE): Norwich, UK, 2001.

3. API. API Recommended Practice: Recommended Practice for Planning, Designing, and Constructing Fixed Offshore Platforms-Working Stress Design (API RP 2A-WSD); American Petroleum Institute (API): Washington, DC, USA, 2007.

4. ISO. Petroleum and Natural Gas Industries- Fixed Steel Offshore Structures (ISO 19902); International Organization for Standardization (ISO): Geneva, Switzerland, 2007.

5. The Norwegian Oil Industry Association. Norsok Standard: Design of Steel Structures (N-004); The Norwegian Oil Industry Association: Norway, Norway, 2013.

6. DNV GL. Support Structures for Wind Turbines (DNVGL-ST-0126); Det Norske Veritas (DNV): HØvik, Norway, 2016. 
7. DNV. Offshore Standard. Design of Offshore Wind Turbine Structures (DNVS-OS-J101); Det Norske Veritas (DNV): HØvik, Norway, 2013.

8. Billington, C.J.; Lewis, G.H. The strength of large diameter grouted connections. In Proceedings of the Offshore Technology Conference, Houston, TX, USA, 8-11 May 1978; pp. 291-301.

9. Billington, C.; Tebbett, I. The basis for new design formulae for grouted jacket to pile connections. In Proceedings of the Offshore Technology Conference, Houston, TX, USA, 5-8 May 1980; pp. 449-458.

10. Karsan, D.I.; Krahl, N.W. New API equation for grouted pile-to-structure connections. In Proceedings of the Offshore Technology Conference, Houston, TX, USA, 7-9 May 1984; pp. 49-56.

11. Lotsberg, I.; Serednicki, A.; Cramer, E.; Bertnes, H.; Haahr, P.E. On the structural capacity of grouted connections in offshore structures. In Proceedings of the ASME 2011 30th International Conference on Ocean, Offshore and Arctic Engineering, Rotterdam, The Netherlands, 19-24 June 2011; pp. 667-677.

12. Dallyn, P.; El-Hamalawi, A.; Palmeri, A.; Knight, R. Knight. Experimental testing of grouted connections for offshore substructures: A critical review. Structures 2015, 3, 90-108. [CrossRef]

13. Dallyn, P.; El-Hamalawi, A.; Palmeri, A.; Knight, R. Experimental investigation on the development of wear in grouted connections for offshore wind turbine generators. Eng. Struct. 2016, 113, 89-102. [CrossRef]

14. Wang, G. The Axial Bearing Capacity of Large-Diameter Grouted Connections for Offshore Wind Turbines. Doctoral Thesis, Zhejiang University, Hangzhou, China, 2017.

15. Zhang, Y.; Wang, G.; Yang, L.; Chen, F.; Jiang, J.; Wang, Z. Axial bearing capacity of high strength grouted connections with shear keys. Acta Energ. Sol. Sin. 2017, 38, 3117-3122.

16. Wimpey Laboratories Limited. Review of Offshore Grout Strengths (Report ST 55/79); Department of Energy: London, UK, 1979.

17. Forsyth, P.; Tebbett, I. New test data on the strength of grouted connections with closely spaced weld beads. In Proceedings of the Offshore Technology Conference, Houston, TX, USA, 2-5 May1988; pp. 237-245.

18. Aritenang, W.; Elnashai, A.S.; Dowling, P.J.; Carroll, B.C. Failure mechanisms of weld-beaded grouted pile/sleeve connections. Mar. Struct. 1990, 3, 391-417. [CrossRef]

19. UK-Department of Energy. Report of the Working Party on the Strength of Grouted Pile/Sleeve Connections for Offshore Structures (OTP- 11); Offshore Technology Publication: London, UK, 1982.

20. UK-Department of Energy. The Strength of Grouted Pile-Sleeve Connections (OTH 86210); Offshore Technology Publication: London, UK, 1986.

21. Lamport, W.B.; Jirsa, J.O.; Yura, J.A. Strength and behavior of grouted pile-to-sleeve connections. J. Struct. Eng. 1991, 117, 2477-2498. [CrossRef]

22. Sele, A.; Skjolde, M. Design Provisions for Offshore Grouted Construction. In Proceedings of the Offshore Technology Conference, Houston, TX, USA, 3-6 May 1993; pp. 165-179.

23. Anders, S.; Lohaus, L. Optimized high-Performance concrete in grouted connections. In Proceedings of the International Fib Symposium, London, UK, 7 May 2008; Volume 8, pp. 369-374.

24. Li, W.; Bian, E.L.; Zhong, W.Q.; Fang, T.; Jiang, P.; Xu, J. Model teset of grouted connection for monopole of offshore wind turbin under static axial load. Hydro Sci. Eng. 2014, 5, 41-46.

25. Lee, J.H.; Won, D.H.; Jeong, Y.J.; Kim, S.H.; Kang, Y.J. Interfacial shear behavior of a high-strength pile to sleeve grouted connection. Eng. Struct. 2017, 151, 704-723. [CrossRef]

(C) 2020 by the authors. Licensee MDPI, Basel, Switzerland. This article is an open access article distributed under the terms and conditions of the Creative Commons Attribution (CC BY) license (http://creativecommons.org/licenses/by/4.0/). 